\title{
Plasma small extracellular vesicles in hypertensive rats impair reactivity of isolated blood vessels
}

\author{
Yusei FUJIOKA ${ }^{1)}$, Kosuke OTANI ${ }^{1)}$, Muneyoshi OKADA ${ }^{1)}$ and \\ Hideyuki YAMAWAKI ${ }^{1) *}$ \\ 1)Laboratory of Veterinary Pharmacology, School of Veterinary Medicine, Kitasato University, Towada, \\ Aomori 034-8628, Japan
}

J. Vet. Med. Sci.

82(7): 897-902, 2020

doi: 10.1292/jvms.20-0208

Received: 12 April 2020

Accepted: 30 April 2020

Advanced Epub: 18 May 2020

\begin{abstract}
Extracellular vesicles (EV) consist of a lipid-bilayered membrane and are typically classified as small EV (sEV or exosome) or large EV (or microvesicle). sEV mediate cell-to-cell communication and play a key role in various disease states. We recently reported that plasma sEV in normotensive Wistar Kyoto rats (WKY) and spontaneously hypertensive rats (SHR), an animal model of human essential hypertension, regulate systemic blood pressure (BP). An abnormal vascular reactivity is involved in the onset and progression of hypertension. In the present study, we tested the hypothesis that plasma sEV may affect the reactivity of isolated blood vessels. sEV were isolated from plasma in male WKY and SHR (WsEV and SsEV, respectively) by precipitation with polyethylene-glycol and ultracentrifugation. The particle distribution and concentration of $\mathrm{sEV}$ were measured by a tunable resistive pulse sensing method. Isolated mesenteric arteries from normal male Wistar rats were cultured for $24 \mathrm{hr}$ with WsEV, SsEV, or vehicle. There was no difference in particle distribution and total concentration between WsEV and SsEV. Both SsEV and WsEV had no significant effect on the KCl-induced maximal contraction, while SsEV specifically attenuated contraction induced by noradrenaline compared with WsEV- and vehicle-treatment. In summary, it was for the first time revealed that SsEV attenuate the agonist-induced contractility of isolated blood vessels, which might be at least partly responsible for the BP regulation by SsEV.

KEY WORDS: blood vessel, organ culture, small extracellular vesicle, spontaneously hypertensive rat, vascular reactivity
\end{abstract}

Extracellular vesicles (EV) are typically classified as small EV (sEV or exosome, with a diameter of approximately 50-150 nm) or large EV (or microvesicles, with a diameter of approximately $50 \mathrm{~nm}-1 \mu \mathrm{m}$ ) [24]. EV consist of a lipid-bilayered membrane and contain various molecules, including proteins, DNA, microRNA, lipids, and metabolites [2, 20]. sEV are arisen from endosomal compartments called multivesicular bodies (MVBs). During the biogenesis of sEV, the membrane of MVBs invaginates inward forming intraluminal vesicles (ILVs). Fusion of the MVBs with the plasma membrane mediates the release of ILVs into the extracellular fluid, which are then referred as sEV [2]. The circulating sEV are mostly uptaken by the tissues where blood vessels are distributed [8] and they do not seem to be excreted through the urine [19]. The released sEV affect cellular function via signal transduction by binding to cell surface receptors and/or delivery of the luggage by phagocytosis, pinocytosis, and membrane fusion. Therefore, sEV are now recognized as the active particles mediating cell-to-cell communication [14, 24].

Recent studies suggest that sEV play a key role in various disease states, including cancer [7], neurodegenerative diseases [6], and cardiovascular diseases [22]. For example, it was reported that bladder cancer cell-derived sEV inhibited tumor cell apoptosis and induced cell proliferation, suggesting that tumor-derived sEV are involved in the progression of bladder cancer [25]. On the other hand, it was reported that non-cancerous cells-derived sEV suppressed the growth of cancer cell [9]. It has also been suggested that the infectious prion protein, a causative agent of prion disease, may be transmitted via sEV [21]. The sEV released by cardiomyocytes after the hypoxic stimulation contain angiotensin II (Ang II) type 1 receptor (AT1R). Then, the administration of this sEV into AT1R knockout mice restored the Ang II-dependent increase in systemic blood pressure (SBP) [18]. More recently, we demonstrated that plasma sEV in normotensive Wistar Kyoto rats (WKY) and spontaneously hypertensive rats (SHR), an animal model of human systemic hypertension (WsEV and SsEV, respectively), regulated SBP [17]. Further, it was recently reported that diabetic mice-derived large EV promoted the signaling pathway that caused the endothelial dysfunction [23]. An abnormal vascular reactivity is involved in the onset and progression of hypertension. In the present study, we then tested

*Correspondence to: Yamawaki, H.: yamawaki@vmas.kitasato-u.ac.jp

(02020 The Japanese Society of Veterinary Science

This is an open-access article distributed under the terms of the Creative Commons Attribution Non-Commercial No Derivatives (by-nc-nd) License. (CC-BY-NC-ND 4.0: https://creativecommons.org/licenses/by-nc-nd/4.0/) 
the hypothesis that SEV may affect the reactivity of isolated blood vessels. As a result, we revealed for the first time that SsEV specifically impaired the agonist-induced contractility of rat isolated mesenteric arteries.

\section{MATERIALS AND METHODS}

\section{Animals}

Animal care and procedures were done in conformity with the institutional guideline of School of Veterinary Medicine, the Kitasato University. This animal study was approved by the ethical committee of School of Veterinary Medicine, the Kitasato University. Male WKY, SHR (Hoshino Laboratory Animals, Inc., Bandou, Japan), and normal Wistar rats (CLEA Japan, Inc., Tokyo, Japan) were used. They can freely take food (CE2, CLEA Japan, Inc.) and tap water.

\section{Measurement of body weight and SBP}

Body weight and SBP of WKY and SHR (8-week-old) were measured after the initial induction and before the use. SBP was measured by a tail cuff method using a non-invasive automatic blood pressure measurement device (BP-98AL; Softron, Tokyo, Japan). We confirmed that SHR exhibited hypertension compared with WKY.

\section{sEV isolation from rat plasma}

sEV were isolated from plasma of WKY (WsEV) and SHR (SsEV) by the precipitation with polyethylene-glycol and ultracentrifugation as previously described $[15,16]$. WKY and SHR (8-week-old) were deeply anesthetized with urethane (SigmaAldrich, St. Louis, MO, USA) (1.5 g/kg, i.p.). Blood was drawn via an inferior vena cava, gently mixed with heparin $(1 \mathrm{U} / \mathrm{m} l)$, and centrifuged (room temperature; RT, $1,000 \mathrm{~g}, 10 \mathrm{~min}$ ) in order to isolate plasma. The plasma samples were centrifuged $\left(4^{\circ} \mathrm{C}, 10,000\right.$ $\mathrm{g}, 10 \mathrm{~min}$ ) to remove large $\mathrm{EV}$, and the supernatants was mixed with an equal volume of sterilized polyethylene-glycol solution by inverting $\left(4^{\circ} \mathrm{C}\right.$, overnight $)$. After centrifugation $\left(4^{\circ} \mathrm{C}, 2,500 \mathrm{~g}, 15 \mathrm{~min}\right)$, the pellets were resuspended in sterilized phosphatebuffered saline (PBS) by vigorous vortex (RT, $30 \mathrm{~min}$ ) and ultracentrifuged $\left(4^{\circ} \mathrm{C}, 164,071 \mathrm{~g}, 35 \mathrm{~min}\right)$ by using an Optima XL-80K ultracentrifuge with a swing rotor SW 55 Ti (Beckman Coulter Inc., Miami, FL, USA). The pellets were resuspended in sterilized PBS and used for the following experiments.

\section{Measurement of particle distribution and concentration of plasma $\mathrm{SEV}$}

Particle distribution and concentration of the isolated sEV were measured by a tunable resistive pulse sensing (TRPS) method using a qNANO instrument with an NP150 nanopore at 46.5-47.5 mm stretch (IZON Science, Christchurch, New Zealand) according to the manufacturer's instruction as previously reported $[15,16]$.

\section{Tissue preparation and organ culture procedure}

Normal male Wistar rats (6-8-week-old) were deeply anesthetized with urethane and euthanized by exsanguination. The main branch of the superior mesenteric artery was isolated under sterile conditions. After removal of fat and adventitia in sterilized Tris-buffered saline (TBS), the mesenteric artery was cut into rings (1-mm in diameter, 2-mm in length) for organ culture and subsequent measurement of isometric contraction. Arterial rings were then placed in $1 \mathrm{~m} l$ serum-free-Dulbecco's Modified Eagle Medium (DMEM) with WsEV, SsEV $\left(8.0 \times 10^{8}\right.$ particles $\left./ \mathrm{m} l\right)$, or vehicle (PBS) supplemented with $1 \%$ penicillin-streptomycin. They were maintained at $37^{\circ} \mathrm{C}$ in an atmosphere of $95 \%$ air and $5 \% \mathrm{CO}_{2}$ for $24 \mathrm{hr}[12,13]$.

\section{Measurement of isometric contraction}

The arterial rings were placed in normal physiological salt solution (PSS), which contained (mM): $\mathrm{NaCl} 139.9, \mathrm{KCl} 5.4, \mathrm{CaCl}_{2}$ $1.5, \mathrm{MgCl}_{2} 1.0, \mathrm{NaHCO}_{3} 23.8$, and glucose 5.5 as reported previously [12, 13]. Ethylenediaminetetraacetic acid (EDTA), $10 \mu \mathrm{M}$, was added to remove the contaminating heavy metal ions which catalyze oxidation of organic chemicals. High $\mathrm{K}^{+}(72.7 \mathrm{mM})$ solutions was prepared by replacing $\mathrm{NaCl}$ with equimolar $\mathrm{KCl}$. These solutions were saturated with a $95 \% \mathrm{O}_{2}-5 \% \mathrm{CO}_{2}$ mixture at $37^{\circ} \mathrm{C}$ and $\mathrm{pH}$ 7.4. Smooth muscle contraction was recorded isometrically with a force-displacement transducer (Nihon Kohden, Tokyo, Japan) after amplifying the signal with ISOMETRIC AMPLIFIER (EF-601G; Nihon Kohden). Each muscle ring was attached to a holder under a resting tension of $0.5 \mathrm{~g}$. After equilibration for $30 \mathrm{~min}$ in a $3 \mathrm{~m} l$ organ bath, each ring was repeatedly exposed to high $\mathrm{K}^{+}(72.4 \mathrm{mM})$ solution until the responses became stable (45-60 $\left.\mathrm{min}\right)$. Concentration-response curves for noradrenaline (NA) were obtained by the cumulative application of NA $(0.1 \mathrm{nM}-3 \mu \mathrm{M})$.

\section{Statistics analysis}

Data were presented as means \pm standard error of the mean (SEM). In two-group comparison, statistical analyses were performed using an unpaired Student's $t$-test. In three-group comparison, statistical analyses were performed with a one- way ANOVA followed by Bonferroni's post-hoc test. To compare concentration-response curves, statistical analyses were performed with a two-way ANOVA followed by Bonferroni's post hoc-test. $P$ values of less than 0.05 were considered statistically significant. 


\section{RESULTS}

\section{Particle distribution and concentration of plasma sEV from WKY and SHR}

We first compared the particle distribution and concentration between WsEV and SsEV. Both of them distributed within the expected size ranges with a diameter of $\sim 100-150 \mathrm{~nm}$, and did not differ as determined by the TRPS analyses (Fig. 1a, 1b, n=3). We also confirmed that there was no significant difference in total concentration (Table $1, \mathrm{n}=3$ ), mean diameter (Table $1, \mathrm{n}=3$ ), and mode (the most frequent) diameter (Table $1, \mathrm{n}=3$ ).

\section{Effects of long-term treatment with WsEV and SsEV on KCl-induced contractile response in rat isolated mesenteric arteries}

We first examined the effects of pretreatment with $\mathrm{sEV}$ on $\mathrm{KCl}$-induced maximal contraction in rat isolated mesenteric arteries.

Pretreatment of mesenteric arteries with WsEV $\left(8.0 \times 10^{8}\right.$ particles $\left./ \mathrm{ml}, 24 \mathrm{hr}\right)$ had no effect on the $\mathrm{KCl}(72.7 \mathrm{mM})$-induced contraction compared with vehicle (PBS)-treatment (Fig. 2, WsEV, $n=8$ vs. PBS, $\mathrm{n}=10$ ). Similarly, pretreatment of mesenteric arteries with SsEV $\left(8.0 \times 10^{8}\right.$ particles $\left./ \mathrm{ml}, 24 \mathrm{hr}\right)$ had no significant effects on the KCl-induced contraction compared with vehicleand WsEV-treatment (Fig. 2, SsEV, n=12).

\section{Effects of long-term treatment with WsEV or SsEV on NA-induced contractile response in rat isolated mesenteric arteries}

We next examined the effects of pretreatment with SEV on NA (a sympathetic neurotransmitter)-induced contraction (relative contraction $[\mathrm{RC}]$ and absolute contraction $[\mathrm{AC}]$ ) of rat isolated mesenteric arteries. Pretreatment of mesenteric arteries with WsEV $\left(8.0 \times 10^{8}\right.$ particles $\left./ \mathrm{ml}, 24 \mathrm{hr}\right)$ had no effect on the NA $(0.1 \mathrm{nM}-3 \mu \mathrm{M})$-induced contraction (both RC and AC) compared with vehicle-treatment (Fig. 3ab, closed circle WsEV, $n=8$ vs. open circle PBS, $n=10$ ). On the other hand, pretreatment of mesenteric arteries with SsEV $\left(8.0 \times 10^{8}\right.$ particles $\left./ \mathrm{ml}, 24 \mathrm{hr}\right)$ significantly attenuated the NA-induced contraction (both RC and AC) compared with vehicle- or WsEV-treatment (Fig. 3ab, closed triangle SsEV, $\mathrm{n}=11-12, P<0.05$ and 0.01 vs. open circle PBS or closed circle WsEV).

a

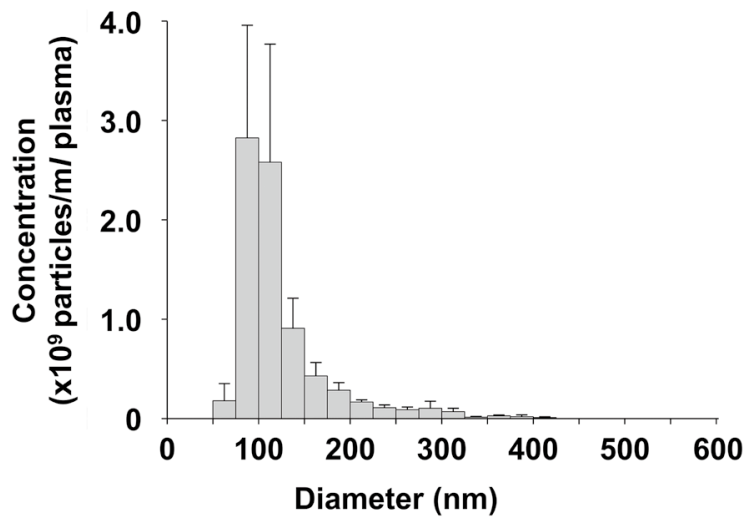

b

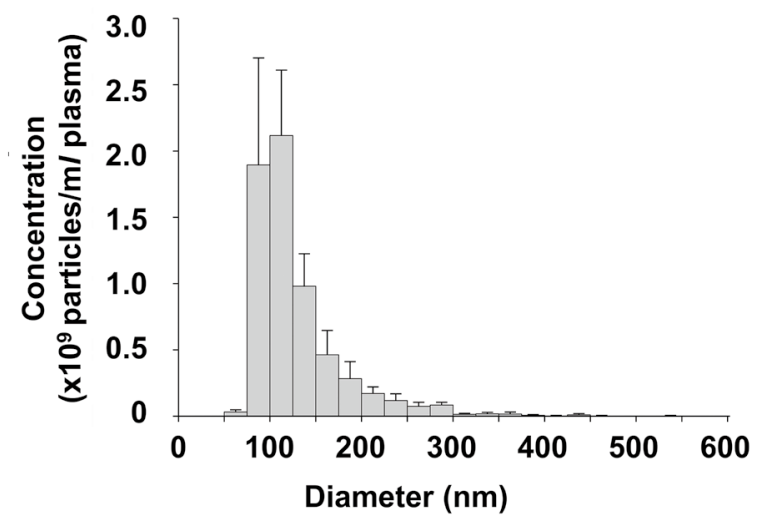

Fig. 1. Particle distribution and concentration of plasma small extracellular vesicles (sEV) from Wistar Kyoto rats (WKY) and spontaneously hypertensive rats (SHR). The sEV were separated from heparin $(1 \mathrm{U} / \mathrm{m} l$ )-treated plasma in male WKY (8-week-old) and SHR (8-week-old) by precipitation with polyethylene-glycol $(8 \%, 12 \mathrm{hr})$ and ultracentrifugation $\left(4^{\circ} \mathrm{C}, 164,071 \mathrm{~g}, 35 \mathrm{~min}\right)$. The particle distribution and concentration of sEV were measured with a tunable resistive pulse sensing analysis. Particle distribution and concentration of plasma sEV from WKY (a) and SHR (b) were shown. Results were expressed as means \pm standard error of the mean $(\mathrm{n}=3)$.

Table 1. Total concentration, mean diameter, and mode diameter of plasma small extracellular vesicles (sEV) from Wistar Kyoto rats and spontaneously hypertensive rats (WsEV and SsEV, respectively)

\begin{tabular}{lcccc}
\hline & \multicolumn{2}{c}{ WsEV } & \multicolumn{2}{c}{ SsEV } \\
\hline Total concentration (particles $/ \mathrm{m} l$ plasma) & $7.8 \pm 2.5 \times 10^{9}$ & $(\mathrm{n}=3)$ & $6.3 \pm 1.9 \times 10^{9}$ & $(\mathrm{n}=3)$ \\
Mean diameter $(\mathrm{nm})$ & $125.3 \pm 9.9$ & $(\mathrm{n}=3)$ & $126.2 \pm 5.5$ & $(\mathrm{n}=3)$ \\
Mode diameter $(\mathrm{nm})$ & $98.0 \pm 6.6$ & $(\mathrm{n}=3)$ & $95.3 \pm 1.2$ & $(\mathrm{n}=3)$ \\
\hline
\end{tabular}

Total concentration, mean diameter, and mode diameter of sEV were measured with a tunable resistive pulse sensing analysis. Results were expressed as means \pm standard error of the mean. 


\section{DISCUSSION}

In the present study, we examined the effects of long-term treatment with WsEV or SsEV (24 hr) on the reactivity of rat isolated mesenteric arteries. The major findings are as follows: 1) There was no significant difference in total concentration, mean diameter, and mode diameter between WsEV and SsEV (Fig. 1, Table 1). 2) WsEV and SsEV had no significant effect on the KCl (72.7 mM)-induced maximal contraction (Fig. 2). 3) WsEV had no effect on the NA (0.1 nM-3 $\mu \mathrm{M}$ )-induced contraction (RC and AC). On the other hand, SsEV significantly attenuated the NA (0.1 nM-3 $\mu \mathrm{M})$-induced contraction (RC and AC) (Fig. 3). From the above results, it was for the first time revealed that long-term treatment with SsEV specifically impaired the agonist-induced contractility of isolated blood vessels. It is known that vascular smooth muscle cell (VSMC) undergoes phenotypic conversion from a contractile to a synthetic state during the cardiovascular diseases including hypertension. Therefore, it is proposed that SsEV may be at least in part responsible for VSMC phenotypic conversion.

In the present study, it was found that total concentration and size distribution in plasma sEV derived from hypertensive rats did not change compared with normotensive rats (Fig. 1, Table 1). It was recently reported that the molecular cargoes changed in

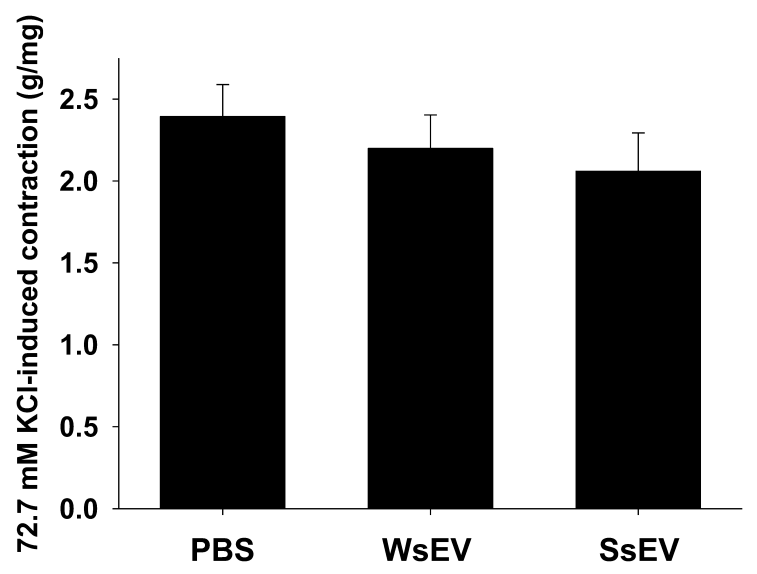

Fig. 2. Effects of long-term (24 hr) treatment with plasma small extracellular vesicles from Wistar Kyoto rats (WsEV) or spontaneously hypertensive rats $(\mathrm{SsEV})\left(8.0 \times 10^{8}\right.$ particles $\left./ \mathrm{m} l\right)$ on $\mathrm{KCl}(72.7 \mathrm{mM})$-induced contractile response in rat isolated mesenteric arteries. Contraction was expressed as an absolute value ( $\mathrm{g} / \mathrm{mg}$ tissue wet weight). Results were expressed as means \pm standard error of the mean $(\mathrm{n}=10$ [phosphate-buffered saline (PBS)], $\mathrm{n}=8$ [WsEV], $\mathrm{n}=12$ [SsEV]).

a

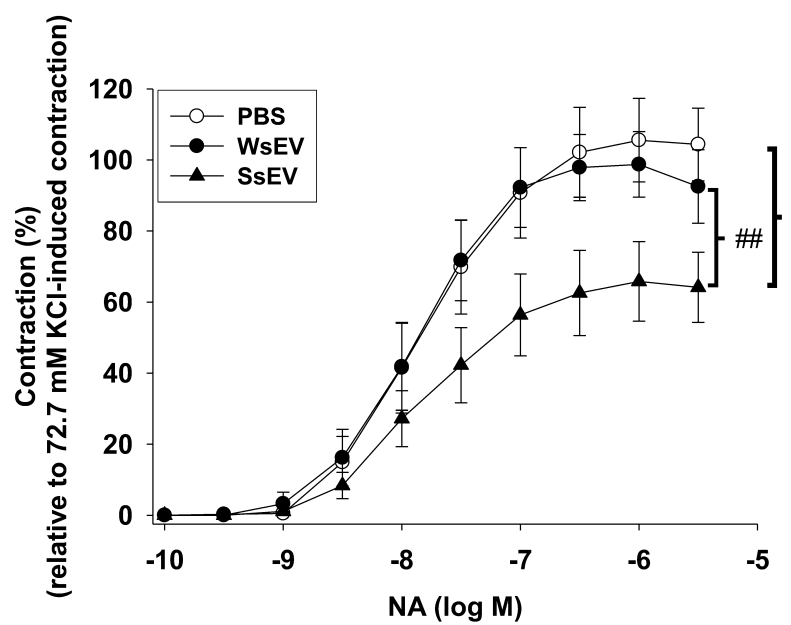

b

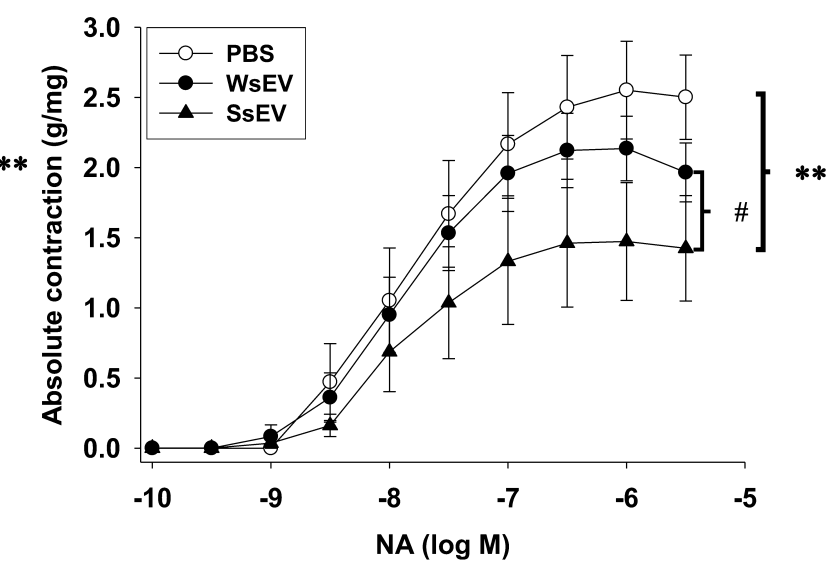

Fig. 3. Concentration-contraction relationship for noradrenaline (NA) in rat isolated mesenteric arteries cultured with plasma small extracellular vesicles from Wistar Kyoto rats (WsEV) or spontaneously hypertensive rats (SsEV) $\left(8.0 \times 10^{8}\right.$ particles/ml) for $24 \mathrm{hr}$. NA $(0.1 \mathrm{nM}-3$ $\mu \mathrm{M})$ was cumulatively applied. Contraction was normalized to the maximal contraction induced by $\mathrm{KCl}(72.7 \mathrm{mM})(\mathrm{a})$ or expressed as an absolute value (b: $\mathrm{g} / \mathrm{mg}$ tissue wet weight). Results were expressed as means \pm standard error of the mean (a: $\mathrm{n}=10$ [phosphate-buffered saline (PBS)], $\mathrm{n}=8$ [WsEV], $\mathrm{n}=12$ [SsEV], $\mathrm{b}: \mathrm{n}=10$ [PBS], $\mathrm{n}=8$ [WsEV], $\mathrm{n}=11$ [SsEV]). ${ }^{* *} P<0.01$ vs. PBS, $\# P<0.05$ and $\# \# P<0.01$ vs. WsEV. 
various disease states without changes in concentration and size distribution of sEV. For example, metabolic syndrome modulated the profiles of mRNA cargo packed within sEV derived from mesenchymal stem cells of porcine adipose tissue [10]. In addition, AT1R-enriched sEV were released by the cardiomyocytes after hypoxic stimulation [18]. From the above reports, it is proposed that the molecular cargoes in plasma sEV from animal models of essential hypertension could change, which needs to be further explored in the future study.

In the present study, we treated the isolated mesenteric arteries with $\mathrm{sEV}$ at $8.0 \times 10^{8} \mathrm{particles} / \mathrm{ml}$ (Figs. 2 and 3). It was reported that the concentration of plasma $\mathrm{sEV}$ in rats was approximately $10^{8}-10^{12}$ particles $/ \mathrm{m} l[4,5,11]$. In addition, previous investigations used EV at wide-ranging concentrations between $10^{5}-10^{10}$ particles $/ \mathrm{m} l[1,3]$. Based on the above reports, the concentration of $\mathrm{sEV}$ used in the present study would be appropriate. In addition, we treated the isolated mesenteric arteries with sEV for $24 \mathrm{hr}$ (Figs. 2 and 3). It remains to be clarified whether sEV are stable in circulation for $24 \mathrm{hr}$. We previously confirmed that sEV were uptaken into VSMC within $2 \mathrm{hr}$ [16] and that they were remaining within the cells after $24 \mathrm{hr}$. Since we focused on the effects of small RNA including microRNA in sEV, which mediates the protein expression in the recipient cells, we examined the long-term effects of sEV. On the other hand, we also need to examine the short-term effects of sEV, since proteins contained in sEV are transferrable within a short period of time.

In the present study, it was found that the long-term treatment of rat isolated mesenteric arteries with SsEV specifically attenuated the NA-induced contraction ( $\mathrm{RC}$ and $\mathrm{AC}$ ) without affecting the $\mathrm{KCl}(72.7 \mathrm{mM})$-induced maximal contraction (Figs. 2 and 3). The mechanism of VSMC contraction by high $\mathrm{K}^{+}$is based on the activation of contractile protein [phosphorylation of myosin light chain (MLC)] by extracellular $\mathrm{Ca}^{2+}$ influx through the opening of voltage-dependent $\mathrm{Ca}^{2+}$ channels by membrane depolarization. On the other hand, NA-induced VSMC contraction is mediated not only through the extracellular $\mathrm{Ca}^{2+}$ influx but also through the inositol trisphosphate $\left(\mathrm{IP}_{3}\right)$-dependent $\mathrm{Ca}^{2+}$ release from sarcoplasmic reticulum via the activation of $\alpha_{1}$ adrenergic receptor- $\mathrm{G}_{\mathrm{q}}$ protein. Therefore, it is suggested that the inhibition of $\alpha_{1}$ adrenergic receptor- $\mathrm{G}_{\mathrm{q}}$ protein- $\mathrm{IP}_{3}-\mathrm{Ca}^{2+}$ release pathway is at least partly responsible for the impaired NA-induced VSMC contraction by SsEV.

In conclusion, it was for the first time revealed that SsEV specifically impair the agonist-induced contractility of isolated blood vessels, which might be at least partly responsible for the blood pressure regulation by SsEV. Further researches are required to elucidate the underlying mechanisms of plasma sEV regulation of etiology of systemic hypertension.

ACKNOWLEDGMENT. This research was partly supported by a research grant from Kitasato University, School of Veterinary Medicine.

\section{REFERENCES}

1. Alibhai, F. J., Lim, F., Yeganeh, A., DiStefano, P. V., Binesh-Marvasti, T., Belfiore, A., Wlodarek, L., Gustafson, D., Millar, S., Li, S. H., Weisel, R. D., Fish, J. E. and Li, R. K. 2020. Cellular senescence contributes to age-dependent changes in circulating extracellular vesicle cargo and function. Aging Cell 19: e13103. [Medline] [CrossRef]

2. Bang, C. and Thum, T. 2012. Exosomes: new players in cell-cell communication. Int. J. Biochem. Cell Biol. 44: 2060-2064. [Medline] [CrossRef]

3. Bao, H., Chen, Y. X., Huang, K., Zhuang, F., Bao, M., Han, Y., Chen, X. H., Shi, Q., Yao, Q. P. and Qi, Y. X. 2018. Platelet-derived microparticles promote endothelial cell proliferation in hypertension via miR-142-3p. FASEB J. 32: 3912-3923. [Medline] [CrossRef]

4. Baranyai, T., Herczeg, K., Onódi, Z., Voszka, I., Módos, K., Marton, N., Nagy, G., Mäger, I., Wood, M. J., El Andaloussi, S., Pálinkás, Z., Kumar, V., Nagy, P., Kittel, Á., Buzás, E. I., Ferdinandy, P. and Giricz, Z. 2015. Isolation of exosomes from blood plasma: Qualitative and quantitative comparison of ultracentrifugation and size exclusion chromatography methods. PLoS One 10: e0145686. [Medline] [CrossRef]

5. Beninson, L. A., Brown, P. N., Loughridge, A. B., Saludes, J. P., Maslanik, T., Hills, A. K., Woodworth, T., Craig, W., Yin, H. and Fleshner, M. 2014. Acute stressor exposure modifies plasma exosome-associated heat shock protein 72 (Hsp72) and microRNA (miR-142-5p and miR-203). PLoS One 9: e108748. [Medline] [CrossRef]

6. Budnik, V., Ruiz-Cañada, C. and Wendler, F. 2016. Extracellular vesicles round off communication in the nervous system. Nat. Rev. Neurosci. 17: 160-172. [Medline] [CrossRef]

7. Hannafon, B. N. and Ding, W. Q. 2013. Intercellular communication by exosome-derived microRNAs in cancer. Int. J. Mol. Sci. 14: 14240-14269. [Medline] [CrossRef]

8. Imai, T., Takahashi, Y., Nishikawa, M., Kato, K., Morishita, M., Yamashita, T., Matsumoto, A., Charoenviriyakul, C. and Takakura, Y. 2015. Macrophage-dependent clearance of systemically administered B16BL6-derived exosomes from the blood circulation in mice. J. Extracell. Vesicles 4: 26238. [Medline] [CrossRef]

9. Kosaka, N., Iguchi, H., Yoshioka, Y., Hagiwara, K., Takeshita, F. and Ochiya, T. 2012. Competitive interactions of cancer cells and normal cells via secretory microRNAs. J. Biol. Chem. 287: 1397-1405. [Medline] [CrossRef]

10. Meng, Y., Eirin, A., Zhu, X. Y., O’Brien, D. R., Lerman, A., van Wijnen, A. J. and Lerman, L. O. 2018. The metabolic syndrome modifies the mRNA expression profile of extracellular vesicles derived from porcine mesenchymal stem cells. Diabetol. Metab. Syndr. 10: 58. [Medline] [CrossRef]

11. Minghua, W., Zhijian, G., Chahua, H., Qiang, L., Minxuan, X., Luqiao, W., Weifang, Z., Peng, L., Biming, Z., Lingling, Y., Zhenzhen, W., Jianqing, X., Huihui, B., Xiaozhong, W. and Xiaoshu, C. 2018. Plasma exosomes induced by remote ischaemic preconditioning attenuate myocardial ischaemia/reperfusion injury by transferring miR-24. Cell Death Dis. 9: 320. [Medline] [CrossRef]

12. Morita, T., Okada, M., Hara, Y. and Yamawaki, H. 2011. Mechanisms underlying impairment of endothelium-dependent relaxation by fetal bovine serum in organ-cultured rat mesenteric artery. Eur. J. Pharmacol. 668: 401-406. [Medline] [CrossRef]

13. Morita, T., Yamawaki, H., Okada, M. and Hara, Y. 2010. Contractile characteristics of rat mesenteric artery after organ culture. J. Vet. Med. Sci. 72: 1621-1627. [Medline] [CrossRef]

14. Mulcahy, L. A., Pink, R. C. and Carter, D. R. F. 2014. Routes and mechanisms of extracellular vesicle uptake. J. Extracell. Vesicles 3: 24641. [Medline] [CrossRef]

15. Otani, K., Fujioka, Y., Okada, M. and Yamawaki, H. 2019. Optimal isolation method of small extracellular vesicles from rat plasma. Int. J. Mol. Sci. 
20: 4780. [Medline] [CrossRef]

16. Otani, K., Yokoya, M., Fujioka, Y., Okada, M. and Yamawaki, H. 2020. Small extracellular vesicles from rat plasma promote migration and proliferation of vascular smooth muscle cells. J. Vet. Med. Sci. 82: 299-306. [Medline] [CrossRef]

17. Otani, K., Yokoya, M., Kodama, T., Hori, K., Matsumoto, K., Okada, M. and Yamawaki, H. 2018. Plasma exosomes regulate systemic blood pressure in rats. Biochem. Biophys. Res. Commun. 503: 776-783. [Medline] [CrossRef]

18. Pironti, G., Strachan, R. T., Abraham, D., Mon-Wei Yu, S., Chen, M., Chen, W., Hanada, K., Mao, L., Watson, L. J. and Rockman, H. A. 2015. Circulating exosomes induced by cardiac pressure overload contain functional angiotensin II type 1 receptors. Circulation 131: 2120-2130. [Medline] [CrossRef]

19. Ranghino, A., Dimuccio, V., Papadimitriou, E. and Bussolati, B. 2015. Extracellular vesicles in the urine: markers and mediators of tissue damage and regeneration. Clin. Kidney J. 8: 23-30. [Medline] [CrossRef]

20. Raposo, G. and Stoorvogel, W. 2013. Extracellular vesicles: exosomes, microvesicles, and friends. J. Cell Biol. 200: 373-383. [Medline] [CrossRef]

21. Saá, P., Yakovleva, O., de Castro, J., Vasilyeva, I., De Paoli, S. H., Simak, J. and Cervenakova, L. 2014. First demonstration of transmissible spongiform encephalopathy-associated prion protein (PrPTSE) in extracellular vesicles from plasma of mice infected with mouse-adapted variant Creutzfeldt-Jakob disease by in vitro amplification. J. Biol. Chem. 289: 29247-29260. [Medline] [CrossRef]

22. Sahoo, S. and Losordo, D. W. 2014. Exosomes and cardiac repair after myocardial infarction. Circ. Res. 114: 333-344. [Medline] [CrossRef]

23. Taguchi, K., Narimatsu, H., Matsumoto, T. and Kobayashi, T. 2019. ERK-containing microparticles from a diabetic mouse induce endothelial dysfunction. J. Endocrinol. 241: 221-233. [Medline] [CrossRef]

24. van Niel, G., D’Angelo, G. and Raposo, G. 2018. Shedding light on the cell biology of extracellular vesicles. Nat. Rev. Mol. Cell Biol. 19: 213-228. [Medline] [CrossRef]

25. Yang, L., Wu, X. H., Wang, D., Luo, C. L. and Chen, L. X. 2013. Bladder cancer cell-derived exosomes inhibit tumor cell apoptosis and induce cell proliferation in vitro. Mol. Med. Rep. 8: 1272-1278. [Medline] [CrossRef] 